\title{
The effect of apolipoprotein E deficiency on islet amyloid deposition in human islet amyloid polypeptide transgenic mice
}

\author{
J. Vidal ${ }^{1,2}$, C. Bruce Verchere ${ }^{1,2}$, S. Andrikopoulos ${ }^{1,2}$, F. Wang ${ }^{1,2}$, R. L. Hull ${ }^{1,2}$, M. Cnop ${ }^{1,2}$, K. L. Olin ${ }^{1}$, \\ R. C. LeBoeuf ${ }^{1,3,4}$, K. D. O'Brien ${ }^{5}$, A. Chait ${ }^{1}$, S. E. Kahn ${ }^{1,2}$ \\ ${ }^{1}$ Division of Metabolism, Endocrinology and Nutrition, Department of Medicine, University of Washington, Seattle, Washington, USA \\ 2 VA Puget Sound Health Care System, South Columbian Way, Seattle, USA \\ ${ }^{3}$ Department of Pathobiology, University of Washington, Seattle, Washington, USA \\ ${ }^{4}$ Department of Nutritional Sciences, University of Washington, Seattle, Washington, USA \\ ${ }^{5}$ Division of Cardiology, Department of Medicine, University of Washington, Seattle, Washington, USA
}

\section{Abstract}

Aims/hypothesis. Islet amyloid deposits are present in over $85 \%$ of Type 2 diabetic patients and have been suggested to be pathogenic. The mechanism that converts islet amyloid polypeptide (IAPP), the unique component of these deposits, into amyloid fibrils in vivo is not known. The amino acid sequence of IAPP is critical but insufficient for beta-pleated sheet formation. As apolipoprotein E (apoE), another component of islet amyloid deposits, plays a critical role in amyloid formation in Alzheimer's disease, we hypothesised that apoE could play an important role in islet amyloid formation.

Methods. Transgenic mice expressing the human form of IAPP $\left(h I A P P^{+/ 0}\right)$ were crossbred with apoE deficient $\left(a p o E^{-/}\right)$mice and followed for 12 months, at which time the prevalence and severity of islet amyloid, as well as plasma glucose, hIAPP, immunoreactive insulin (IRI) and lipid concentrations were measured.
Results. The prevalence and severity of islet amyloid after one year of follow up were comparable among $h I A P P^{+/ 0}$ mice that were $a p o E^{+/+}, a_{p o E^{+/-}}$or $a p o E^{-/-}$. Differences in glucose tolerance, lipid abnormalities or changes in pancreatic content or plasma concentrations of hIAPP and/or IRI did not account for these findings.

Conclusion/interpretation. Our data shows that, unlike in the localized amyloidosis in the brain characteristic of Alzheimer's disease, apoE is not critical for islet amyloid formation in a transgenic mouse model of Type 2 diabetes mellitus. These results indicate that the mechanisms of localised amyloid formation probably vary among different amyloid-associated disorders. Therefore, therapeutic strategies targeting apoE might not apply equally to patients with different amyloid associated diseases. [Diabetologia (2003) 46:71-79]

Keywords Islet amyloid, islet amyloid polypeptide, amylin, apolipoprotein E, diabetes, Alzheimer's disease.
Received: 30 July 2002 / Accepted: 16 August 2002 Published online: 9 January 2003

CC Springer-Verlag 2003

Corresponding author: S. E. Kahn, Division of Metabolism, Endocrinology and Nutrition, Department of Medicine, University of Washington, Seattle, Washington, USA, E-mail: skahn@ u.washington.edu

Abbreviations: IAPP, Islet amyloid polypeptide; hIAPP, human islet amyloid polypeptide; hIAPP-LI, human islet amyloid polypeptide-like immunoreactivity; mIAPP-LI, mouse islet amyloid polypeptide-like immunoreactivity; ApoE, apolipoprotein E; IRI, immunoreactive insulin; IPGTT, intraperitoneal glucose tolerance test.
Localised amyloid deposits are a pathological hallmark of several diseases such as Type 2 diabetes mellitus and Alzheimer's disease [1,2]. Islet amyloid deposits are present in over $85 \%$ of human subjects with Type 2 diabetes mellitus [3] and have been suggested to be pathogenic. The exact mechanism that converts islet amyloid polypeptide (IAPP), the unique component of these deposits $[4,5]$, into amyloid fibrils in vivo is not known [1]. The amino acid sequence of the IAPP molecule is critical for beta-pleated sheet formation. However, an amyloidogenic IAPP sequence is not sufficient for islet amyloid formation since islet amyloid deposits are rarely observed in non-diabetic people even in the presence of increased IAPP production and secretion, as seen in obesity [6]. 
To study factors that could be important in the development of islet amyloid in Type 2 diabetes, we and several other groups have developed transgenic mouse models expressing the human form of IAPP (hIAPP) in their beta cells $[7,8,9,10]$. The human IAPP molecule contains a specific sequence of amino acids rendering it capable of forming amyloid fibrils, while this amyloidogenic sequence is absent in rodents, thus explaining the lack of islet amyloid in diabetic rats and mice [1]. Our human IAPP transgenic mice maintain normal beta-cell secretory function and two-thirds of them develop islet amyloid after 12 months on a highfat diet [11]. Therefore, these features make this animal model suitable to study factors implicated in islet amyloidogenesis.

In recent years apolipoprotein $\mathrm{E}$ (apoE), another component of amyloid deposits, has been shown to play a critical role in amyloid formation in Alzheimer's disease $[12,13,14]$. In animal models of the disease, it has been shown that apoE plays a pivotal role in determining the amount and anatomical distribution of amyloid $\beta(A \beta)$ deposition $[12,13]$. Moreover, in humans the $\varepsilon 4$ apoE genotype has been associated with a younger age of onset of Alzheimer's disease and increased amyloid burden in post-mortem neuropathological studies [15]. Since autopsy samples from Type 2 diabetic subjects have shown the presence of apoE in islet amyloid deposits, it has been suggested that apoE could play an important role in islet amyloid formation $[1,16]$. To test this hypothesis, we crossbred transgenic mice expressing the human form of IAPP $\left(h I A P P^{+/ 0}\right)$ with apoE deficient $\left(a p o E^{-/}\right)$mice and compared the prevalence and severity of islet amyloid among the $h I A P P^{+/ 0}$ transgenic mice with different apoE genotypes.

\section{Materials and methods}

Mice. The hemizygous transgenic mice used for our study expressed the hIAPP gene driven by the rodent insulin 2 promoter in their islet beta cells and were on a C57BL/6 x DBA/2 hybrid background [11]. ApoE $E^{-/}$mice on a C57BL/6 background [17] were obtained from Jackson Laboratories (Bar Harbor, Me., USA). Animals were housed in the Animal Research Facility at the Seattle Veterans Affairs Puget Sound Health Care System (SVAPSHCS) on a 12-h light to dark cycle at $22^{\circ} \mathrm{C}$. Mice were fed chow containing $21 \%$ fat (w/w; D12290; Research Diets, N.J., USA). The Animal Review Committee at the SVAPSHCS approved the study and the principles of laboratory animal care were followed.

The presence of the hIAPP transgene and the disrupted apoE gene in the offspring was determined by the polymerase chain reaction of tail DNA using transgene specific primers. For genotyping of the hIAPP gene, the sense primer was 5'-AGA TGA GAG AAG CTG GTA TTT CTC A-3' and the antisense primer was $5^{\prime}$-AGA TGA GAG AAT GGC ACC AAA- $3^{\prime}$. The hIAPP transgene resulted in a 182-bp band. For genotyping of the apoE gene, the following primers were used: 5'-GCC TAG CCG AGG GAG GC CG, 5'-TGT GAC TTG GGA GCT CTG CAG C, and 5'-GCC GCC CCG ACT GCA
TCT. The wild-type allele resulted in a 155-bp band and the knockout a 245 -bp band. For both reactions, denaturing was done at $94^{\circ} \mathrm{C}$ for $30 \mathrm{~s}$, followed by 35 cycles of annealing at $68^{\circ} \mathrm{C}(25 \mathrm{~s})$ and extension at $72^{\circ} \mathrm{C}(60 \mathrm{~s})$.

Histochemical analysis. Pancreases were excised after 12 months of follow up. Two thirds of the pancreas was fixed overnight in $4 \%$ paraformaldehyde and embedded in paraffin for histological analysis. The other third was snap frozen in liquid nitrogen and stored at $-70^{\circ} \mathrm{C}$ for peptide content analysis. For thioflavin S staining, five $\mu \mathrm{m}$ sections were incubated with $0.5 \%$ thioflavin S for $2 \mathrm{~min}$, rinsed in $70 \%$ ethanol, washed in water and mounted [11]. The areas of immunoreactivity for amyloid in islets (at least 15 per mouse) were quantified at $\times 200$ magnification using a computerised image analysis system. The imaging system was composed of a fluorescence microscope (Axioplan, Zeiss, Germany) equipped with a charge-coupled device camera operating at 10 bits (Hamamatsu C4880, Photonics, Japan), linked to a computer-based imaging system supported by the software MCID-M2 (Image Research Inc., St. Catharines, Ontario, Canada). For each islet, total and thioflavin $\mathrm{S}$ positive areas were measured. From these data, the proportion of mice containing at least one islet positive for islet amyloid, amyloid prevalence and severity were calculated [18]. Amyloid prevalence was defined as the proportion of islets containing amyloid per mouse (number of islets containing amyloid/total number of islets scored per mouse $\times 100$ ). Amyloid severity was assessed as the proportion of total islet area that was occupied by amyloid in each mouse ( amyloid area/ $/$ islet area $\times 100$ ) [18]. ApoE was localised using rabbit antiserum raised against mouse apoE (titre 1:1000 in Tris-HCl buffer, $\mathrm{pH}$ 7.4; Biodesign International, Kennebunk, Me., USA). After an overnight incubation with the primary antibody, sections were rinsed in phosphate buffered saline (PBS) for 15 min and incubated for $1 \mathrm{~h}$ with goat anti rabbit secondary antisera (titre 1:200; Jackson ImmunoResearch, West Grove, Pa., USA) conjugated with indocarbocyanine (Cy3).

Islet isolation. Islets were isolated from mice by collagenase digestion. In brief, after euthanization of the mice by cervical dislocation, the pancreas was harvested and minced $(2 \mathrm{~min})$ in ice-cold HBSS, then incubated in $2 \mathrm{mg} / \mathrm{ml}$ collagenase (Type XI, Sigma, St. Louis, Mo., USA) for $15 \mathrm{~min}$ at $37^{\circ} \mathrm{C}$, followed by a second incubation of 10 to $15 \mathrm{~min}$ in collagenase plus $1.3 \mathrm{mg} / \mathrm{ml}$ DNAse (Sigma). The digestion was stopped by dilution in ice-cold HBSS plus $0.1 \%$ BSA. After partial purification on a Ficoll gradient, the islets were handpicked twice under a dissecting microscope.

Western blot analysis. ApoE in mouse lipoproteins and islets was evaluated by SDS polyacrylamide gel electrophoresis and western blotting. Mouse lipoproteins $(\mathrm{d}<1.21 \mathrm{~g} / \mathrm{ml})$ were isolated from mouse plasma using density gradient ultracentrifugation, and stored at $-70^{\circ} \mathrm{C}$ until analysed. Islets were isolated into RPMI 1640 media containing $10 \mathrm{mmol} / \mathrm{l}$ HEPES and gentamicin $(50 \mathrm{mg} / \mathrm{l})$, rinsed with Hanks' Balanced Salt Solution and PBS containing PMSF $(0.2 \mathrm{mmol} / \mathrm{l})$ and aprotinin $(10 \mu \mathrm{g} / \mathrm{ml})$, and stored at $-70^{\circ} \mathrm{C}$ in PBS until analysed for apoE. Prior to apoE analysis, PBS was removed by centrifugation, and the islets solubilized by briefly sonicating in $8 \mathrm{M}$ urea/0.5\% (w/w) Triton X-100. Lipoprotein and islet samples were electrophoresed on $4-12 \%$ polyacrylamide gels under reducing conditions and electrophoretically transferred to nitrocellulose. Blots were probed with a rabbit anti-mouse apoE antibody (titre 1:2000; Biodesign International), followed by incubation with rabbit $\operatorname{IgG}$ peroxidase (titre 1:5000; Boehringer-Mannheim, Indianapolis, Ind., USA). The presence 
of apoE was then detected using enhanced chemiluminescence (Renaissance Detection Kit; NEN Life Sciences, Boston, Mass., USA).

Pancreas extraction procedure. Samples of pancreas were homogenized in 50\% isopropanol/1\% trifluoroacetic acid and incubated at $4{ }^{\circ} \mathrm{C}$ for 4 to $8 \mathrm{~h}$. After a freeze-thaw cycle at $-70^{\circ} \mathrm{C}$, the homogenate was centrifuged at $13000 \mathrm{rpm}$ for $15 \mathrm{~min}$ and peptide content of immunoreactive insulin (IRI), hIAPP-like immunoreactivity (hIAPP-LI) and mouse IAPPlike immunoreactivity (mIAPP-LI) were measured in the supernatant.

Intraperitoneal glucose tolerance test (IPGTT). At 12 months of age, mice were fasted overnight (18 h) and were anaesthetised with an intraperitoneal injection (100 $\mathrm{mg} / \mathrm{kg}$ body weight) of sodium pentobarbital (Nembutal; Abbot Laboratories, North Chicago, Ill., USA). A glucose bolus ( $1 \mathrm{~g} / \mathrm{kg}$ body weight) was injected intraperitoneally $40 \mathrm{~min}$ after the anaesthesia was injected. Blood was drawn into heparinized capillary tubes from the retro-orbital sinus before and 15, 30, 60 and 120 min after glucose administration. The plasma was separated by centrifugation and stored at $-20^{\circ} \mathrm{C}$ until assayed for glucose and IRI.

Plasma measurements. One week after the IPGTT, animals were fasted for $4 \mathrm{~h}$ and then anaesthetised as described above. Forty min after the induction of anaesthesia, blood was collected from the orbital sinus using heparinized capillary tubes, centrifuged, and plasma separated and stored at $-20^{\circ} \mathrm{C}$ until assayed for glucose, IRI, hIAPP-LI and mIAPP-LI, triglycerides, and total-, VLDL-, LDL- and HDL-cholesterol concentrations.

Assays. Plasma glucose was assayed using the glucose oxidase method.

IRI was measured by a double-antibody radioimmunoassay using rat insulin as the standard. The assay has an intra-assay coefficient of variation (CV) of $6.4 \%$ and an inter-assay $\mathrm{CV}$ of $12 \%$ [19]. mIAPP-LI was measured with a radioimmunoassay using an in-house antibody (8342), high-performance liquid chromatography purified ${ }^{125}$ I-labelled rodent IAPP, and rodent IAPP as standard (Peninsula, Belmont, Calif., USA). The assay has an intra-assay $\mathrm{CV}$ of $9 \%$ and an inter-assay $\mathrm{CV}$ of $12 \%$ [19]. hIAPP-LI was assayed using an enzyme-linked immunoabsorbance assay, using F024 as the capture antibody and F002 as the detection antibody (Amylin Pharmaceuticals, San Diego, Calif., USA). F002 specifically recognises human and not mouse IAPP, such that samples that do not specifically contain hIAPP read zero in this assay. The CVs for this assay are less than $10 \%$ for intra-assay and less than $15 \%$ inter-assay variation [20].

Plasma cholesterol concentrations were measured using a colorimetric kit (Diagnostic Chemicals, Oxford, Conn., USA) and cholesterol standards (Preciset No. 12552, Boehringer Mannheim). Plasma triglyceride concentrations were measured colorimetrically after free glycerol was removed (diagnostic kit No. 450032, Boehringer Mannheim). Plasma lipoproteins were separated by fast-performance liquid chromatography gel filtration on a Superose 6 column (Pharmacia LKB Biotechnology, Sweden). A $100 \mu$ l aliquot of plasma from each mouse was analysed at a flow rate of $0.2 \mathrm{ml} / \mathrm{min}$ with PBS at $4{ }^{\circ} \mathrm{C}$ for cholesterol fractions measurements. Aliquots $(100 \mu \mathrm{l})$ from each of the $0.5 \mathrm{ml}$ fractions were used for total cholesterol and triglyceride determinations [21].

Calculations and statistical analyses. The total area under the curve for the glucose and insulin responses during the IPGTT was calculated using the trapezoidal method.
Data are presented as means \pm SEM. Comparisons between continuous variables were done by using the Kruskal-Wallis or Mann-Whitney U test. Categorical data were compared using Chi-squared analysis. Simple regression analysis was done to analyse the relation between lipid concentrations and amyloid severity. A $p$ value of less than 0.05 was considered significant.

\section{Results}

ApoE is not critical for islet amyloid formation in vivo. To assess whether apoE is critical for islet amyloid formation in vivo, we crossed apoE-deficient mice $\left(a p o E^{-/-}\right)$with transgenic mice expressing human IAPP $\left(h I A P P^{+/ 0}\right)$ in their pancreatic beta cells and obtained heterozygous mice that were subsequently intercrossed. Littermates of the following progeny were selected for characterisation: $h I A P P^{+/ 0} \mathrm{x}$ apoE $E^{+/+}$ $(n=11) ; h I A P P^{+/ 0} \times$ apoE $^{+/-}(n=18) ;$ and $h I A P P^{+/ 0} \times$ apoE $E^{-/}(n=11)$. Because we have previously shown that islet amyloid forms primarily in male $h I A P P^{+/ 0}$ transgenic mice when they are fed a high-fat diet for 1 year [11], we only studied male mice fed a $21 \%$ fat (w/w) diet for 12 months from weaning. Mice nontransgenic for hIAPP were not included because mouse IAPP (mIAPP) is not amyloidogenic and consequently islet amyloid is never observed in wild-type mice $[11,19,22]$.

In the first set of studies, consecutive pancreatic sections from $h I A P P^{+/ 0} \mathrm{x}$ apoE ${ }^{+/+}, h I A P P^{+/ 0} \mathrm{x}$ $a p o E^{+/-}$, and $h I A P P^{+/ 0} \times$ x $a p o E^{-/-}$mice ( $n=6$ per group) were stained for amyloid and apoE. In pancreatic sections from $h I A P P^{+/ 0}$ mice that had one or both apoE alleles, thioflavin $\mathrm{S}$-fluorescence (indicative of amyloid) and apoE immunoreactive areas were co-localised (Fig. 1), indicating the presence of apoE in islet amyloid deposits. Thioflavin S-fluorescent amyloid deposits were also found in $h I A P P^{+/ 0} \times \mathrm{apoE}^{-/-}$mice though, as expected, apoE immunoreactivity was not.

To investigate whether apoE influenced the extent of islet amyloid formation, the proportion of mice containing at least one islet positive for islet amyloid and the prevalence and severity of islet amyloid were assessed histologically after thioflavin S staining using a quantitative imaging system. Islet amyloid deposits were present in 7 out of $11(64 \%) h I A P P^{+/ 0} \mathrm{x}$ $a p o E^{+/+}$mice studied. The proportion of mice with islets positive for amyloid was not reduced in hIAPP transgenic mice lacking one or both apoE alleles. Thioflavin S staining was positive in 14 out of 18 (78\%) IAPP transgenic mice that were $a p o E^{+/}$, and in 9 out of $11(82 \%)$ transgenic mice that were $a p o E^{-/}$ ( $p=0.58$ compared to $h I A P P^{+/ 0}$, apoE $E^{+/+}$mice). Similarly, the prevalence and severity of islet amyloid assessed as the proportion of islets per mouse that were positive for amyloid and the percentage of islet area occupied by amyloid respectively did not differ among the three groups (Fig. 2). 


\section{apoE genotype}

$$
+/+
$$
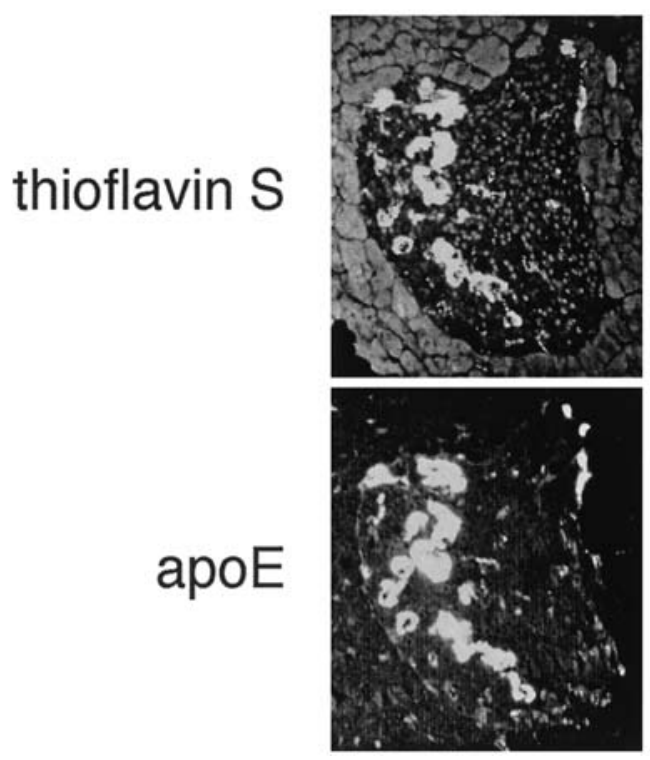

Fig. 1. Thioflavin S positive islet amyloid deposits form in the presence and absence of apoE. Consecutive pancreatic sections from $h I A P P^{+/ 0}$ transgenic mice that are $a p o E^{+/+}$, apo $E^{+/-}$or $a p o E^{-/-}$were stained with thioflavin $\mathrm{S}$ for amyloid or with an antibody for apoE. Thioflavin $S$ positive amyloid deposits were present regardless of the apoE genotype. ApoE immunoreactivity co-localised with amyloid deposits in $a p o E^{+/+}$and apo $E^{+/-}$mice and, as expected, is absent in $a p o E^{-/-}$mice
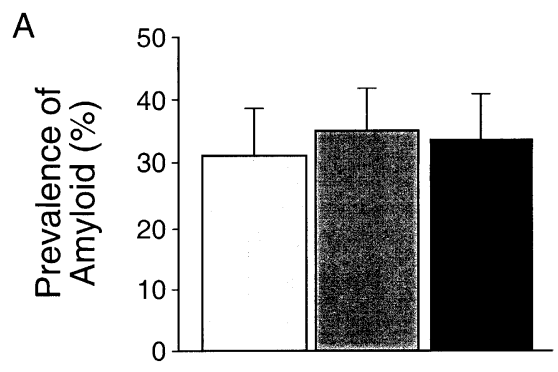

B

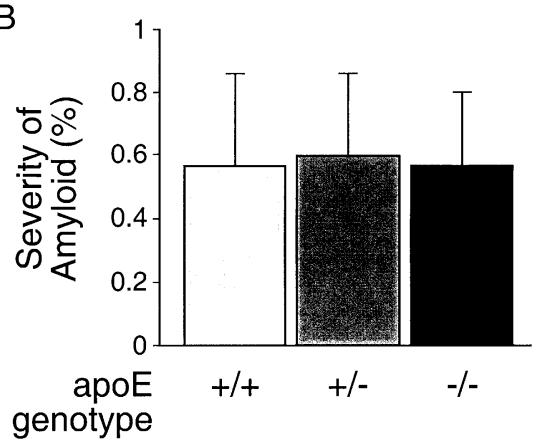

Fig. 2A, B. Amyloid prevalence (A) and severity (B) in hIAPP transgenic mouse pancreas did not differ among mice with different apoE genotypes. Data are presented as meansZZZ; $\pm Z Z Z$;SEM
$+/-$
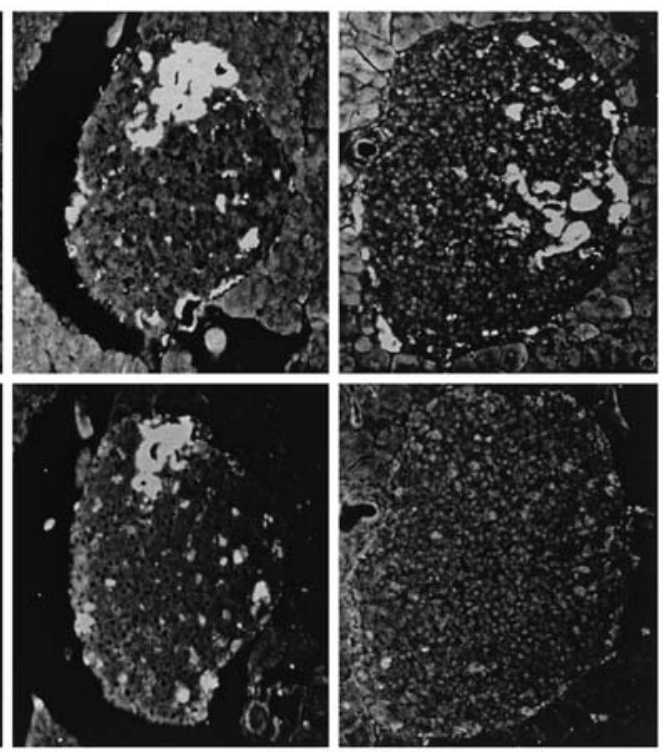

ApoE genotype is not associated with changes in pancreatic content or secretion of the amyloidogenic form of IAPP. To examine whether the lack of differences in amyloid deposition among the three study groups could be attributed to alterations in the expression and/or secretion of hIAPP in mice lacking both apoE alleles, we quantified pancreatic peptide content of hIAPP, mIAPP, and insulin in samples from all mice as well as plasma hIAPP and insulin $4 \mathrm{~h}$ after food withdrawal [19]. When adjusted for total protein content, no significant differences in hIAPP-LI or mIAPP-LI were found among the different groups (Table 1). Similarly, IRI content was not affected by the apoE genotype with the ratio between hIAPP-LI or mIAPP-LI and IRI being similar among the three study groups. Plasma IRI and hIAPP-LI also did not differ among the three groups $4 \mathrm{~h}$ after food withdrawal (Table 2).

Lipid abnormalities associated with the apoE genotype and islet amyloid deposition. Because of the central role of apoE in plasma lipoprotein and cholesterol transport, apoE knockout mice have profound lipid abnormalities [17, 23]. Consistent with those reports, $h I A P P^{+/ 0} \times$ apoE $E^{-/}$mice had threefold higher plasma cholesterol concentrations than their apoE wild-type littermates (Table 2). This marked hypercholesterolaemia was largely the result of increased concentrations of very low (VLDL) and low-density (LDL) lipoproteins and was already present at three months of age. Similarly, $h I A P P^{+/ 0} \times$ apoE $E^{-/}$mice had nearly fourfold lower high density lipoprotein (HDL) and more than twofold higher triglyceride concentrations than $h I A P P^{+/ 0} \times a_{0 o E^{+/-}}$or $h I A P P^{+/ 0} \times a^{2} E^{+/+}$mice.

To assess whether the abnormalities in plasma lipid concentrations could have influenced our findings, we compared plasma total cholesterol and triglyceride 
A

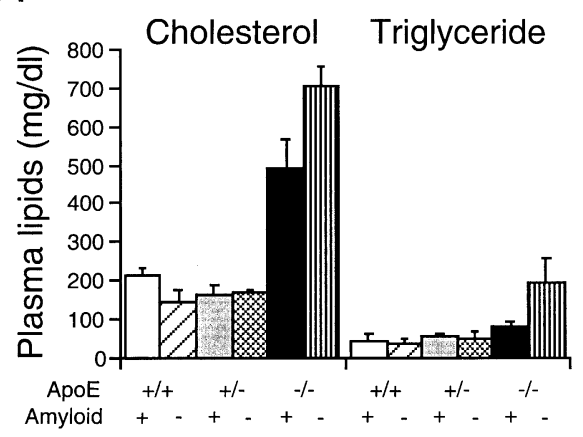

Fig. 3A, B. Plasma lipid concentrations associated with the apoE genotype have no major effect on islet amyloid deposition. Concentrations of total plasma cholesterol and triglyceride (A) and very low density (VLDL), low density (LDL), and
B

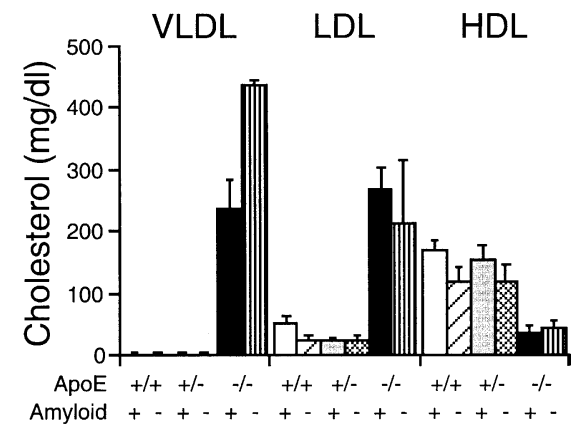

high density (HDL) cholesterol (B) measured $4 \mathrm{~h}$ after food withdrawal did not differ within each genotype whether amyloid was present ( $n=4$ per group) or amyloid was absent $(n=2-3$ per group). Data are presented as means \pm SEM

Table 1. Pancreatic content of IRI, mouse IAPP-LI, and hIAPP-LI in hIAPP transgenic mice at 12 months follow up

\begin{tabular}{|c|c|c|c|}
\hline & $h I A P P^{+/ 0} \times$ apoE $+/+(n=11)$ & $h I A P P^{+/ 0} \times$ apoE ${ }^{+/-}(n=18)$ & $h I A P P^{+/ 0} \times$ apoE $E^{-/-}(n=11)$ \\
\hline mIAPP-LI (pmol $1^{-1} \mu \mathrm{g}^{-1}$ protein) & $9.0 \pm 1.8$ & $10.5 \pm 2.3$ & $7.4 \pm 1.9$ \\
\hline hIAPP-LI (pmol $1^{-1} \mu \mathrm{g}^{-1}$ protein) & $7.9 \pm 1.3$ & $10.0 \pm 2.1$ & $7.8 \pm 2.1$ \\
\hline hIAPP-LI/IRI (\%) & $3.0 \pm 0.4$ & $2.7 \pm 0.3$ & $2.1 \pm 0.3$ \\
\hline mIAPP-LI/IRI (\%) & $3.1 \pm 0.3$ & $2.9 \pm 0.3$ & $2.2 \pm 0.4$ \\
\hline
\end{tabular}

Data are meansZZZ; $\pm Z Z Z ; S E M$

Table 2. 4-h fasting plasma measurements in hIAPP transgenic mice at 12 months of follow up

\begin{tabular}{|c|c|c|c|}
\hline & $h I A P P^{+/ 0} \times$ apoE ${ }^{+/+}$ & $h I A P P^{+/ 0} \times$ apoE $E^{+/-}$ & $h I A P P^{+/ 0} \times$ apoE $E^{-/-}$ \\
\hline Glucose (mmol/l) & $11.2 \pm 0.8$ & $12.6 \pm 0.9$ & $14.6 \pm 2.4$ \\
\hline IRI (pmol/l) & $588.1 \pm 131.6$ & $1139.9 \pm 274.5$ & $815.5 \pm 336.0$ \\
\hline hIAPP-LI/IRI (\%) & $17.1 \pm 4.5$ & $12.0 \pm 1.6$ & $20.2 \pm 5.9$ \\
\hline Cholesterol (mmol/l) & $4.76 \pm 0.53$ & $4.37 \pm 0.35$ & $14.3 \pm 1.64 \mathrm{a}, \mathrm{b}$ \\
\hline VLDL-cholesterol (mmol/l) & $0.05 \pm 0.03$ & $0.04 \pm 0.03$ & $7.54 \pm 1.29 \mathrm{a}, \mathrm{b}$ \\
\hline Triglycerides $(\mathrm{mmol} / \mathrm{l})$ & $0.51 \pm 0.11$ & $0.65 \pm 0.09$ & $1.31 \pm 0.31 \mathrm{c}, \mathrm{d}$ \\
\hline
\end{tabular}

Data are meansZZZ; $\pm Z Z Z ; S E M . ~{ }^{\mathrm{a}} p<0.01 h I A P P^{+/ 0} \mathrm{x}$ apoE -/-vs $h I A P P^{+/ 0} \mathrm{x}$ apoE ${ }^{+/+} ;{ }^{\mathrm{b}} p<0.01 h I A P P^{+/ 0} \mathrm{x}$ apoE $-/-\mathrm{vs} h I A P P^{+/ 0} \mathrm{x}$ apoE ${ }^{+/} ;{ }^{c} p<0.05 h I A P P^{+/ 0} \times$ apoE ${ }^{-/-}$vs $h I A P P^{+/ 0} \times$ apoE ${ }^{+/+} ;{ }^{\mathrm{d}} p<0.05 h I A P P^{+/ 0} \mathrm{x}$ apoE ${ }^{-/-}$vs $h I A P P^{+/ 0}$ apoE ${ }^{+/-}$

concentrations between mice positive and negative for islet amyloid within each of the three study groups. Although the low number of mice without islet amyloid limits this analysis, total cholesterol and triglyceride concentrations did not differ in mice with or without amyloid within each genotype (Fig. 3A). Furthermore, no differences were observed in any of the different cholesterol fractions between mice with or without amyloid within each genotype (Fig. 3B). If anything, the triglycerides and VLDL concentration tended to be higher in the $h I A P P^{+/ 0} \times \mathrm{apoE}^{-/-}$mice without amyloid. Moreover, no significant correlation was found between plasma lipid concentrations and the percentage of islet area occupied by amyloid in any of the three study groups.
Islet amyloid deposition is not associated with differences in glucose tolerance in hIAPP ${ }^{+/ 0}$ mice with different apoE genotypes. To exclude the possibility that differences in glucose tolerance could have influenced the observed results, an IPGTT was carried out at 12 months of age, 1 week before the mice were killed. Body weights at 1 year follow-up did not differ among

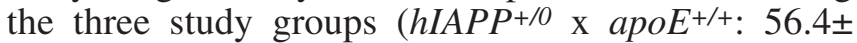
$3.4 \mathrm{~g} ; h_{I A P P^{+/ 0}}$ x apoE ${ }^{+/-}: 58.5 \pm 1.7 \mathrm{~g} ; h I A P P^{+/ 0} \mathrm{x}$ apo $E^{--}$: $59.6 \pm 2.0 \mathrm{~g}$ ). Overnight fasting and poststimulation plasma glucose and IRI concentrations were not different among the groups (Fig. 4A, B). Consequently, neither glucose nor IRI areas under the curve differed among the three study groups (Fig. 5A, B). 
A

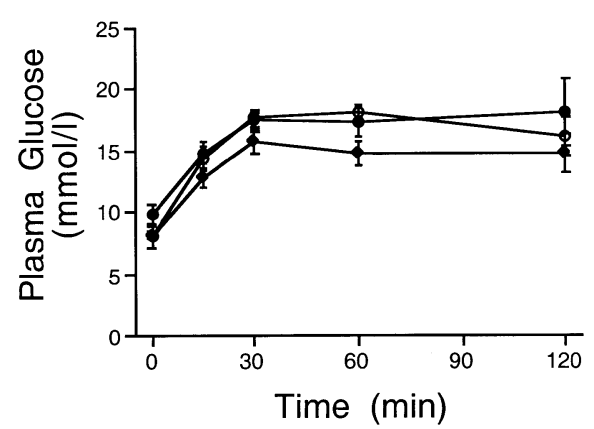

Fig. 4A, B. Glucose tolerance and insulin secretion after an intraperitoneal glucose injection $(1 \mathrm{~g} / \mathrm{kg}$ body weight) were not different among $h I A P P^{+/ 0}$ transgenic mice with different apoE genotypes. Plasma glucose concentrations (A) and immunoreactive insulin $(\mathbf{B})$ in $h I A P P^{+/ 0} \times a^{+/+}$(solid circle),

A

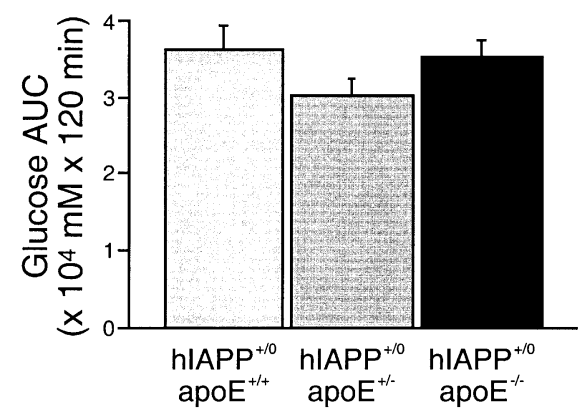

Fig. 5A, B. Intraperitoneal glucose tolerance test (IPGTT) glucose (A) and insulin (B) total areas under the curve (AUC) were not different among $h I A P P^{+/ 0}$ transgenic mice with different apoE genotypes. Data are presented as means \pm SEM

\section{Mouse Mouse \\ Plasma Islets}

\section{$34 \mathrm{KDa}$}

Fig. 6. Western blot analysis of apoE protein in plasma and pancreatic islet extracts from $a p o E^{+/+}$mice. ApoE protein was not present in apo $^{+/+}$mouse islets

ApoE in islet amyloid is not locally synthesised. The absence of apoE immunoreactivity in endocrine islet cells in any of the mice we studied (Fig. 1) would suggest that apoE in pancreatic islets is not locally synthesised by endocrine cells even in the presence of islet amyloid. Supporting our immunohistochemical findings, western blot analysis did not show the presence of apoE in islet extracts from $a p o E^{+/+}$mice (Fig. 6).

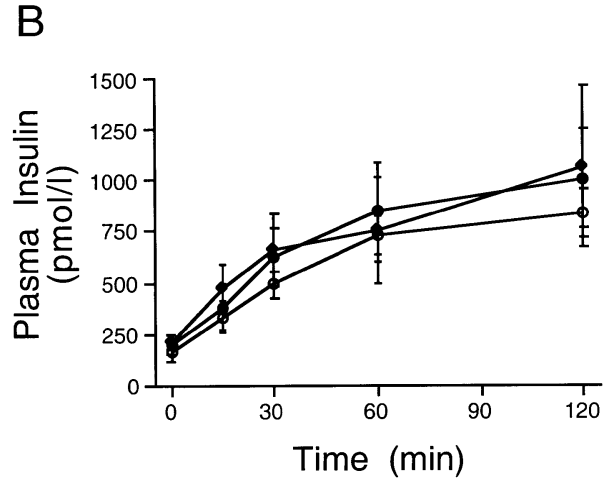

$h I A P P^{+/ 0} \times$ apoE $E^{+/}$(solid diamond) and $h I A P P^{+/ 0} \times$ apoE $E^{-/}$ (open square). Each point represents the means \pm SEM of all mice in each group, which did not differ at any time point among groups

B

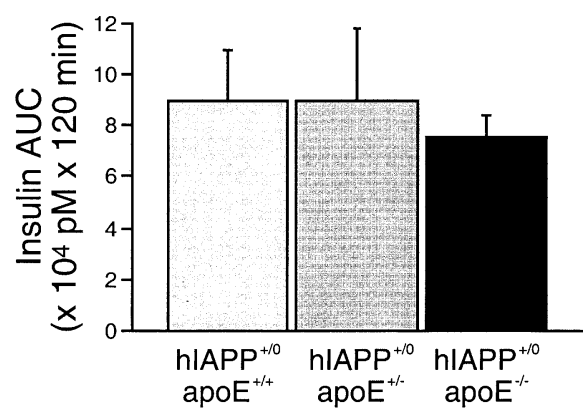

\section{Discussion}

Islet amyloid is the pathological hallmark of Type 2 diabetes. However, the mechanisms underlying islet amyloid formation are poorly understood [1]. A large body of work has been done on the role of IAPP in islet amyloidosis. These studies have not been conclusive, suggesting that other factors are important in islet amyloid deposition. Examination of autopsy samples from people with Type 2 diabetes has shown the presence of at least two additional components in islet amyloid: apoE $[1,16]$ and the heparan sulfate proteoglycan perlecan $[1,24]$. Since both have been identified not only in islet amyloid but also as components of other forms of localised amyloidosis, it has been suggested that they could be important in localised amyloid deposition and that common mechanisms could underlie different forms of amyloidosis [25].

We aimed to evaluate the role of apoE in islet amyloid formation. Evidence from mouse models of Alzheimer's disease strongly suggest that apoE plays an essential role in $A \beta$ deposition in the brain $[12,13]$. It has been postulated that in Alzheimer's disease, apoE promotes both the deposition and fibrillization of $A \beta$ [26]. Moreover, these experimental data are supported by the strong association between the apoE4 allele and an increased age-adjusted risk of developing Alzheimer's disease when compared to subjects who inherit the more common apoE alleles [27]. 
Our data shows that in sharp contrast to what has been reported in Alzheimer's disease, apoE is not critical for islet amyloid formation in vivo.

Because of the lack of suitable small-animal models of islet amyloidogenesis, we cross-bred our hIAPP transgenic mice with apoE deficient mice to test our hypothesis. As expected, islet amyloid was detected in $h I A P P^{+/ 0} \times$ apoE $^{+/+}$mice. The proportion of male hIAPP transgenic mice with both apoE alleles that were positive for islet amyloid was similar to what we have reported in animals fed a relatively high-fat diet [11]. The co-localisation of thioflavin S-fluorescence and apoE immunoreactivity confirmed data showing that this apolipoprotein is a component of islet amyloid $[12,13]$. However, unexpectedly the prevalence of islet amyloid in mice lacking one or both apoE alleles did not differ from that observed in $h I A P P^{+/ 0} \mathrm{x}$ apoE $E^{+/+}$mice. This is opposite to findings in transgenic mouse models of Alzheimer's disease, in which no thioflavin S positive amyloid deposits were observed in mice lacking apoE $[12,13]$.

The development of thioflavin $\mathrm{S}$ positive amyloid deposits in the brain in transgenic mouse models of Alzheimer's disease expressing both apoE alleles is an age-dependent process [26]. In this same mouse model, apoE deficiency is associated with a dramatic dose-dependent decrease in amyloid deposition at all time points of follow up, with amyloid deposits being absent in $a p o E^{-/-}$mice even after 22 months. We quantified islet amyloid deposition only after mice had consumed the high-fat diet for 1 year. Although our experimental protocol did not allow us to do a time-course analysis, two findings support the concept that apoE does not play a critical role in our transgenic mouse model of islet amyloid. First, we did not observe an apoE dosedependent effect on islet amyloid formation. Second, not only were thioflavin $\mathrm{S}$ positive amyloid deposits observed in $h I A P P^{+/ 0} \times$ apoE $^{-/}$mice, but the prevalence and severity of islet amyloid assessed either as the proportion of islets containing amyloid per mouse and the proportion of total islet area that was occupied by amyloid respectively did not differ from that observed in littermates expressing both apoE alleles.

Although islet amyloid deposits are rarely observed in non-diabetic humans in the presence of increased IAPP production and secretion, as seen in obesity [6], experimental data has suggested that IAPP fibril formation could be related to the amount of secretion of the amyloidogenic peptide $[10,19,28]$. The pancreatic peptide content and the plasma concentrations of hIAPP-LI, mIAPP-LI and IRI in the mice in our study would strongly suggest that the absence of apoE does not decrease the synthesis nor the secretion of the amyloidogenic peptide in our model of islet amyloidosis. These data are consistent with that in mouse models of Alzheimer's disease where it has been shown that the absence of apoE does not affect the processing of $\mathrm{A} \beta$, the amyloidogenic peptide in Alzheimer's disease [12, 26].
As expected, hIAPP transgenic mice lacking both apoE alleles showed profound alterations in plasma lipid concentrations. Alterations in plasma cholesterol and its metabolism have been proposed as a risk factor for Alzheimer's disease [29, 30]. Moreover, experimental data support a role for cholesterol in brain metabolism of $A \beta[31]$ and its deposition as amyloid in Alzheimer's disease. Data on the effects of lipid abnormalities on islet amyloid deposition are scarce, although experimental data would suggest that insulin resistance and dyslipidaemia precede islet amyloid formation [32]. Although we acknowledge that our analysis on the effects of lipid abnormalities on amyloid formation is limited by the low number of mice without islet amyloid, the lack of differences in plasma lipid concentrations between mice with or without amyloid within each genotype would argue against lipid abnormalities as an explanation for the deposition of islet amyloid despite the lack of apoE.

Because glucose is known to be a regulator of both IAPP and insulin genes [33], it has been proposed that hyperglycaemia could accelerate islet amyloid formation. Islets isolated from mice expressing the hIAPP gene when cultured at a high glucose concentration contain IAPP-immunoreactive fibrillar material visible by electron microscopy [34]. In our study, overnight fasting glucose and the area under the curve of glucose during the IPGTT did not differ among $h I A P P^{+/ 0}$ mice with different apoE genotypes. Therefore, it is unlikely that differences in glucose tolerance among the three study groups influenced islet amyloid deposition. Although there are no previous reports that directly address the effect of the absence of apoE on glucose tolerance, these data are in line with the lack of an association between the different apoE genotypes and the prevalence and severity of diabetes as reported in human studies $[35,36]$.

Finally, we addressed the question of the origin of apoE in islet amyloid deposits. In Alzheimer's disease, the apoE present in amyloid deposits in neuritic plaques is thought to be synthesised and secreted locally in the brain [14]. In contrast, our findings would argue against a local origin of the apoE in islet amyloid deposits as we failed to find apoE immunoreactivity in endocrine islet cells in any of the apoE wild type mice we studied. These findings are consistent with some, but not all, of the previous reports on this topic. ApoE immunoreactivity has been reported in mouse, monkey and human islets in the absence of amyloid [16, 37]. However, we and others have not observed apoE immunoreactivity in amyloid-free human or monkey islets $[1,38]$. Moreover, our immunohistochemical findings are supported by the absence of apoE in islet extracts from wild type mice as assessed by Western blot analysis.

Thus, our data suggest that apoE is not a critical constituent of islet amyloid in a hIAPP transgenic mouse model of islet amyloid. Although this finding does not 
preclude the involvement of other lipoproteins (e.g. Apo-A1, apoJ) in islet amyloid formation [39, 40], it strongly suggests that apoE in particular is not required for islet amyloidogenesis in Type 2 diabetes. This finding regarding apoE is consistent with the lack of association between the different human apoE isoforms and the incidence and severity of Type 2 diabetes in humans $[35,36]$. This observation sharply contrasts with that concerning the role of apoE in humans and in mouse models of Alzheimer's disease [12, 13, 14], where the apoE genotype contributes both to the age of onset and the severity of the amyloid burden. ApoE is believed to play a pivotal role in the redistribution of lipid and cholesterol during neuronal membrane repair and has been postulated to be important for maintaining neuronal plasticity especially after neuronal injury [41]. Therefore, it is tempting to speculate that the importance of apoE in the brain could account at least in part for its importance as a determinant of deposition of $A \beta$ as amyloid, compared to its role in amyloid formation in the islet where no specific physiological role has been attributed to the lipoprotein. Furthermore, we suggest that the role of apoE in amyloidogenesis could differ among different localised amyloidoses. Together with differences associated with sex in the susceptibility to amyloid deposition in animal models of Alzheimer's disease [42] and Type 2 diabetes [11], we propose that the mechanisms underlying amyloidogenesis could be more divergent than previously thought $[25,43]$. Identification of these differences could be critical to delineate specific therapies to reduce amyloid burden in diseases characterised by local amyloid deposition such as Type 2 diabetes mellitus.

Acknowledgements. We thank M. Abrahamson, R. Vogel, Y. McCutchen, M. Watts, J. Wade, R. Hollingworth, C. Vick, C. Fernstrom and S. Wang for their excellent technical assistance. Amylin Pharmaceuticals kindly donated kits for hIAPP measurement. This work was supported by the National Institutes of Health grants DK-02456, DK-17047, DK-50703, HL-30086, HL-52848, AG10917, the Medical Research Service of the Department of Veterans Affairs and the American Diabetes Association. J. Vidal was supported by a Spanish Ministry of Science and Technology Post-Doctoral Fellowship. F. Wang was supported by a McAbee Fellowship from the Diabetes Research Council. M. Cnop was supported by a Fellowship from the Belgian American Educational Foundation.

\section{References}

1. Kahn SE, Andrikopoulos S, Verchere CB (1999) Islet amyloid: a long-recognized but underappreciated pathological feature of type 2 diabetes. Diabetes 48:241-253

2. Kisilevsky R (1998) Amyloid beta threads in the fabric of Alzheimer's disease. Nat Med 4:772-773

3. Westermark P (1972) Quantitative studies on amyloid in the islets of Langerhans. Ups J Med Sci 77:91-94

4. Westermark P, Wernstedt C, O'Brien TD, Hayden DW, Johnson KH (1987) Islet amyloid in type 2 human diabetes mellitus and adult diabetic cats contains a novel putative polypeptide hormone. Am J Pathol 127:414-417
5. Cooper GJ, Willis AC, Clark A, Turner RC, Sim RB, Reid KB (1987) Purification and characterization of a peptide from amyloid-rich pancreases of type 2 diabetic patients. Proc Natl Acad Sci USA 84:8628-8632

6. Clark A, Saad MF, Nezzer T et al. (1990) Islet amyloid polypeptide in diabetic and non-diabetic Pima Indians. Diabetologia 33:285-289

7. D'Alessio DA, Verchere CB, Kahn SE et al. (1994) Pancreatic expression and secretion of human islet amyloid polypeptide in a transgenic mouse. Diabetes 43:1457-1461

8. Fox N, Schrementi J, Nishi M et al. 1993 Human islet amyloid polypeptide transgenic mice as a model of non-insulindependent diabetes mellitus (NIDDM). FEBS Lett 323:40-44

9. Couce M, Kane LA, O'Brien TD et al. (1996) Treatment with growth hormone and dexamethasone in mice transgenic for human islet amyloid polypeptide causes islet amyloidosis and beta-cell dysfunction. Diabetes 45:1094-1101

10. Höppener JW, Oosterwijk C, Nieuwenhuis MG et al. (1999) Extensive islet amyloid formation is induced by development of Type II diabetes mellitus and contributes to its progression: pathogenesis of diabetes in a mouse model. Diabetologia 42:427-434

11. Verchere CB, D'Alessio DA, Palmiter RD et al. (1996) Islet amyloid formation associated with hyperglycemia in transgenic mice with pancreatic beta cell expression of human islet amyloid polypeptide. Proc Natl Acad Sci USA 93:3492-3496

12. Bales KR, Verina T, Dodel RC et al. (1997) Lack of apolipoprotein E dramatically reduces amyloid beta-peptide deposition. Nat Genet 17:263-264

13. Irizarry MC, Cheung BS, Rebeck GW, Paul SM, Bales KR, Hyman BT (2000) Apolipoprotein E affects the amount, form, and anatomical distribution of amyloid beta-peptide deposition in homozygous APP(V717F) transgenic mice. Acta Neuropathol (Berl) 100:451-458

14. Weisgraber KH, Mahley RW (1996) Human apolipoprotein E: the Alzheimer's disease connection. FASEB J 10:1485-1494

15. Schmechel DE, Saunders AM, Strittmatter WJ et al. (1993) Increased amyloid beta-peptide deposition in cerebral cortex as a consequence of apolipoprotein E genotype in late-onset Alzheimer disease. Proc Natl Acad Sci USA 90:9649-9653

16. Charge SB, Esiri MM, Bethune CA, Hansen BC, Clark A (1996) Apolipoprotein E is associated with islet amyloid and other amyloidoses: implications for Alzheimer's disease. J Pathol 179:443-447

17. Zhang SH, Reddick RL, Piedrahita JA, Maeda N (1992) Spontaneous hypercholesterolemia and arterial lesions in mice lacking apolipoprotein E. Science 258:468-471

18. Wang F, Hull RL, Vidal J, Cnop M, Kahn SE (2001) Islet amyloid develops diffusely throughout the pancreas before becoming severe and replacing endocrine cells. Diabetes 50:2514-2520

19. Andrikopoulos S, Verchere CB, Terauchi Y, Kadowaki T, Kahn SE (2000) Beta-cell glucokinase deficiency and hyperglycemia are associated with reduced islet amyloid deposition in a mouse model of type 2 diabetes. Diabetes 49:2056-2062

20. Percy AJ, Trainor DA, Rittenhouse J, Phelps J, Koda JE (1996) Development of sensitive immunoassays to detect amylin and amylin-like peptides in unextracted plasma. Clin Chem 42:576-585

21. Kirk EA, Dinauer MC, Rosen H, Chait A, Heinecke JW, LeBoeuf RC (2000) Impaired superoxide production due to a deficiency in phagocyte NADPH oxidase fails to inhibit atherosclerosis in mice. Arterioscler Thromb Vasc Biol 20:1529-1535 
22. Kahn SE, Andrikopoulos S, Verchere CB, Wang F, Hull RL, Vidal J (2000) Oophorectomy promotes islet amyloid formation in a transgenic mouse model of Type II diabetes. Diabetologia 43:1309-1312

23. Plump AS, Smith JD, Hayek T et al. (1992) Severe hypercholesterolemia and atherosclerosis in apolipoprotein E-deficient mice created by homologous recombination in ES cells. Cell 71:343-353

24. Park K, Verchere CB (2001) Identification of a heparin binding domain in the N-terminal cleavage site of pro-islet amyloid polypeptide. Implications for islet amyloid formation. J Biol Chem 276:16611-16616

25. Westermark P (1998) The pathogenesis of amyloidosis: understanding general principles. Am J Pathol 152:11251127

26. Bales KR, Verina T, Cummins DJ et al. (1999) Apolipoprotein $\mathrm{E}$ is essential for amyloid deposition in the APP(V717F) transgenic mouse model of Alzheimer's disease. Proc Natl Acad Sci USA 96:15233-15238

27. Corder EH, Saunders AM, Risch NJ et al. (1994) Protective effect of apolipoprotein E type 2 allele for late onset Alzheimer disease. Nat Genet 7:180-184

28. MacArthur DL, de Koning EJ, Verbeek JS, Morris JF, Clark A (1999) Amyloid fibril formation is progressive and correlates with beta-cell secretion in transgenic mouse isolated islets. Diabetologia 42:1219-1227

29. Jarvik GP, Wijsman EM, Kukull WA, Schellenberg GD, Yu C, Larson EB (1995) Interactions of apolipoprotein E genotype, total cholesterol level, age, and sex in prediction of Alzheimer's disease: a case-control study. Neurology 45:1092-1096

30. Prince M, Lovestone S, Cervilla J et al. (2000) The association between APOE and dementia does not seem to be mediated by vascular factors. Neurology 54:397402

31. Bodovitz S, Klein WL (1996) Cholesterol modulates alphasecretase cleavage of amyloid precursor protein. J Biol Chem 271:4436-4440

32. Wagner JD, Cline JM, Shadoan MK, Bullock BC, Rankin SE, Cefalu WT (2001) Naturally occurring and experimental diabetes in cynomolgus monkeys: a comparison of carbohydrate and lipid metabolism and islet pathology. Toxicol Pathol 29:142-148
33. Macfarlane WM, Campbell SC, Elrick LJ et al. (2000) Glucose regulates islet amyloid polypeptide gene transcription in a PDX-1 and calcium-dependent manner. J Biol Chem 275:15330-15335

34. Koning EJ de, Morris ER, Hofhuis FM et al. (1994) Intraand extracellular amyloid fibrils are formed in cultured pancreatic islets of transgenic mice expressing human islet amyloid polypeptide. Proc Natl Acad Sci USA 91:8467-8471

35. Eto M, Watanabe K, Makino I, Ishii K (1991) Apolipoprotein $\mathrm{E}$ allele frequencies in non-insulin-dependent diabetes mellitus with hypertriglyceridemia (type IIb, III, IV, and V hyperlipoproteinemia). Metabolism 40:776-780

36. Inamdar PA, Kelkar SM, Devasagayam TP, Bapat MM (2000) Apolipoprotein E polymorphism in non-insulindependent diabetics of Mumbai, India and its effect on plasma lipids and lipoproteins. Diabetes Res Clin Pract 47:217-223

37. Lin CT, Xu YF, Wu JY, Chan L (1986) Immunoreactive apolipoprotein $\mathrm{E}$ is a widely distributed cellular protein. Immunohistochemical localization of apolipoprotein $\mathrm{E}$ in baboon tissues. J Clin Invest 78:947-958

38. Nakamura S, Kiatipattanasakul W, Nakayama H et al. (1996) Immunohistochemical study on the deposition of apolipoprotein $\mathrm{E}$ in cerebral and islet amyloidoses in cynomolgus monkeys (Macaca fascicularis). Exp Anim 45:199-203

39. Kida E, Choi-Miura NH, Wisniewski KE (1995) Deposition of apolipoproteins $\mathrm{E}$ and $\mathrm{J}$ in senile plaques is topographically determined in both Alzheimer's disease and Down's syndrome brain. Brain Res 685:211-216

40. Wisniewski KE, Ghiso J, Frangione B (1997) Biology of A beta amyloid in Alzheimer's disease. Neurobiol Dis 4:328

41. Boyles JK, Zoellner CD, Anderson LJ et al. (1989) A role for apolipoprotein E, apolipoprotein A-I, and low density lipoprotein receptors in cholesterol transport during regeneration and remyelination of the rat sciatic nerve. J Clin Invest 83:1015-1031

42. Callahan MJ, Lipinski WJ, Bian F, Durham RA, Pack A, Walker LC (2001) Augmented senile plaque load in aged female beta-amyloid precursor protein-transgenic mice. Am J Pathol 158:1173-1177

43. Kisilevsky R, Fraser PE (1997) A beta amyloidogenesis: unique, or variation on a systemic theme? Crit Rev Biochem Mol Biol 32:361-404 